Article

\title{
A Probabilistic and Value-Based Planning Approach to Assess the Competitiveness between Gas-Fired and Renewables in Hydro-Dominated Systems: A Brazilian Case Study
}

\author{
Felipe Nazaré ${ }^{1}$, Luiz Barroso ${ }^{2}$ and Bernardo Bezerra ${ }^{3, *}$ \\ 1 Electrical Engineering Department, Pontifícia Universidade Católica do Rio de Janeiro (PUC-RJ), \\ Rio de Janeiro 22541-041, Brazil; felipelucasnazare@gmail.com \\ 2 Instituto de Investigación Tecnológica, Escuela Técnica Superior de Ingeniería (ICAI), Universidad Pontificia \\ Comillas, 28015 Madrid, Spain; luiz.barroso@comillas.edu \\ 3 Omega Geração S.A., R. Elvira Ferraz, 68, São Paulo 04552-040, Brazil \\ * Correspondence: bebezerra@gmail.com
}

\section{check for}

updates

Citation: Nazaré, F.; Barroso, L.; Bezerra, B. A Probabilistic and Value-Based Planning Approach to Assess the Competitiveness between Gas-Fired and Renewables in Hydro-Dominated Systems: A Brazilian Case Study. Energies 2021, 14, 7281. https://doi.org/10.3390/ en14217281

Academic Editor:

Dimitrios Katsaprakakis

Received: 16 September 2021

Accepted: 30 October 2021

Published: 3 November 2021

Publisher's Note: MDPI stays neutra with regard to jurisdictional claims in published maps and institutional affiliations.

Copyright: (c) 2021 by the authors. Licensee MDPI, Basel, Switzerland. This article is an open access article distributed under the terms and conditions of the Creative Commons Attribution (CC BY) license (https:/ / creativecommons.org/licenses/by/ $4.0 /)$.

\begin{abstract}
The main challenge with the penetration of variable renewable energy (VRE) in thermaldominated systems has been the increase in the need for operating reserves, relying on dispatchable and flexible resources. In the case of hydro-dominated systems, the cost-effective flexibility provided by hydro-plants facilitates the penetration of VRE, but the compounded production variability of these resources challenges the integration of baseload gas-fired plants. The Brazilian power system illustrates this situation, in which the development of large associated gas fields economically depends on the operation of gas-fired plants. Given the current competitiveness of VRE, a natural question is the economic value and tradeoffs for expanding the system opting between baseload gas-fired generation and VRE in an already flexible hydropower system. This paper presents a methodology based on a multi-stage and stochastic capacity expansion model to estimate the optimal mix of baseload thermal power plants and VRE additions considering their contributions for security of supply, which includes peak, energy, and operating reserves, which are endogenously defined in a time-varying and sized in a dynamic way as well as adequacy constraints. The presented model calculates the optimal decision plan, allowing for the estimation of the economical tradeoffs between baseload gas and VRE supply considering their value for the required services to the system. This allows for a comparison between the integration costs of these technologies on the same basis, thus helping policymakers and system planners to better decide on the best way to integrate the gas resources in an electricity industry increasingly renewable. A case study based on a real industrial application is presented for the Brazilian power system.
\end{abstract}

Keywords: power system expansion; co-optimization of energy and reserve; associated natural gas; multi-stage stochastic programming; electricity-gas integration

\section{Introduction}

The integration between electricity and gas started in the $90 \mathrm{~s}$ as a consequence of a widespread construction of new gas-fired power plants, both combined-cycle and opencycle. As competitive, modular, and efficient, the technology was able to displace existing generation in many countries, mostly those already dominated by inefficient and more pollutant thermal generation. This had a perfect fit for investors with the creation of wholesale energy markets launched also in the 1990s: as baseload resources they could secure a volume in the energy spot markets and capture a revenue stream from spot-prices. The baseload dispatch of efficient gas plants also solved the commercial feasibility of the development of oil-gas fields, whose gas supply agreements demand take-or-pay clauses to secure a stable revenue stream to enable the financing of the new gas infrastructure. The combination of a large consumption market for power and non-power uses (industry, 
heating, etc.) engendered a massive integration of gas in the electricity industry in many developed countries and, most importantly, the baseload dispatch of thermal plants secured stable revenue streams for both electricity and gas investors.

The integration of electricity and gas integration was extended to multi-country electricity-gas markets, mostly by Europe. These were a natural evolution to the existing "official" cross-border interconnections, which were originally established by the countries' governments for sharing reserves and carrying out limited economic interchanges. Finally, the development of Liquefied Natural Gas (LNG) has introduced flexibility and removed many physical barriers for the integration of these two markets [1].

While the gas power technology supported the substitution of part of the inefficient thermal power generation in some countries, many others, with significant hydro power generation and access to gas resources (domestic, gas pipelines or LNG imports), have experienced more difficulty in integrating gas-fired plants in the electricity market. Since hydro generation may displace gas-fired plants (even the efficient ones) in the generation merit-order curves depending on meteorological conditions, the demand-side for gas products becomes very dependent on water inflow availability. Therefore, the dispatch of the gas-fired plants has become volatile (for compensating the water inflows), which ends up creating an undesirable (from the gas-sector point of view) variability in natural gas consumption [2].

Whilst the gas-market is still incipient, with a non-power gas use limited, gas supply agreements (GSA) for power generation contracts are typically of long-term with high "take-or-pay" clauses to ensure the financing of the gas production-transportation infrastructure [3]. From the power sector point of view, these clauses are undesirable; due to the uncertainty of dispatch, gas-based power generators aim to negotiate a higher flexibility with gas suppliers in order to become more competitive in the power market while maintaining the "guarantee" of the gas availability whenever the dispatch is needed. This "dilemma" has demanded the development of more flexible supply-demand options, such as LNG-supply with high take-or-pay clauses-to complement the more inflexible options for the gas supply agreements for power generation. This gas supply flexibility is better and easier handled when the demand side of gas industrial is also active, allowing for the explicit pricing of gas surplus by non-power consumers [4].

The increasing participation of variable renewables energy (VRE) resources in this power mix has intensified the issues of variability and uncertainty of the dispatch of all of the technologies, even in the thermal power systems. The increasing need for operating (spinning) reserves has highlighted the value of gas-fired plants as flexible assets. In hydro-dominated countries, the integration of renewables has also increased the value of hydropower as flexibility providers.

When it comes to power system planning, the competition for system expansion between renewables and gas-fired plants has increased. On the one hand, the increasing VRE participation implies the need for sustaining the energy balance through greater amounts of reliable and flexible power resources, which, from the gas-fired plants point of view, increases the variability of the dispatch, resulting in higher take-or-pay clauses on the gas supply agreements. This is also a characteristic of hydro-dominated systems. On the other hand, the competitiveness of "inflexible" gas-fired plants faces greater challenges, especially for those plants whereby the source of gas comes from associated gas fields, where a constant gas flow is required to ensure oil production, avoiding reinjection costs. Hence, defining the optimal tradeoff between variable resources with backup supply or inflexible power generation, also considering aspects of reliability and flexibility needs, became an interesting challenge.

This paper presents a methodology based on a multi-stage and stochastic capacity expansion planning model to determine the competitiveness of a given technology against an existing system, considering its reliability contribution, for peak, energy, and ancillary services. Our work applies this methodology to calculate the tradeoffs between base-loaded gas supply and VRE supply, considering their value for these adequacy and operating 
services in the system. This allows for a comparison between the integration costs of these technologies on the same basis, thus helping policymakers to better decide on the best way to integrate the gas resources in an electricity industry increasingly renewable. A case study based on a real industrial application is presented for the Brazilian power system.

\subsection{The Brazilian Power System and Problem Description}

Brazil is the largest country in Latin America with a power sector containing an installed capacity of $170,000 \mathrm{MW}$. In the $1990^{\prime}$ s, hydro plants were responsible for more than $90 \%$ of power generation in. These plants had some important characteristics for supply reliability, such as flexible output and cheap ancillary services-which is fundamental to any power system in handling unexpected imbalances in real-time operation. On the other hand, a hydro-dominated system needs firm energy backup to deal with dry years, and the Brazilian strategy in the early 2000's started to import natural gas from Bolivia with take-or-pay clauses to remunerate the gas infrastructure investments, while developing offshore natural gas fields.

This integration between natural gas and electricity faced some difficulties in the 2004-2006 period due to the thermal dispatch volatility [1,2,5] and, in 2007, the country started to import LNG to provide greater flexibility for the thermal power plants (TPP), enabling an energy backup during dry periods. This strategy was also adopted by other countries in Latin America, for geopolitical reasons and for a better integration between gas and power $[1,4]$.

Well documented by the International Renewable Energy Agency (IRENA) [6], in the late 2000's Brazil started a renewable auction program for long-term energy contracts, which was responsible for a massive penetration of wind plants. One of the reasons for the auction success was the hydro-domination of the system [7], which reduced the integration cost and ensured very competitive prices for wind generation. In 2014, Brazil started longterm contract auctions for solar energy with similar success and a pathway to integrated renewables to the grid was initiated.

However, due to environmental and social constraints, Brazil's hydro expansion in the last 20 years has only been based on run-of-river hydro plants. The storage capacity of the system compared to the total energy consumption [8] has thus decreased. Along with increasing transmission bottlenecks in the country, this has adversely affected the system operation, increasing the need for other dispatchable alternatives to accommodate the increasing flexibility needs due to the ongoing and expanding integration VRE. Figure 1 below depicts the evolution of the supply mix between 1990 and 2021 considering consolidated values.

In recent years, Brazil has been considering different alternatives to (re)introduce resources for flexibility in the power sector [9]. From alternatives of flexible power plants to the development of green hydrogen and increasing the transmission system in view of diminishing the variability from generation and demand sides and using the power reserves from distant areas, the planning studies focused on alternatives for integrating VRE into the power sector.

On the other hand, the country has giant offshore oil reserves, in the so-called pre-salt fields, with associated natural gas to the oil production. These are located up to $300 \mathrm{~km}$ from the coast and $3000 \mathrm{~m}$ below sea level. These gas and oil fields were discovered in 2008 and, in 2019, they contributed to $62 \%$ of Brazil's total oil production and $57 \%$ of natural gas production. The pre-salt is geographically highlighted in Figure 2. 


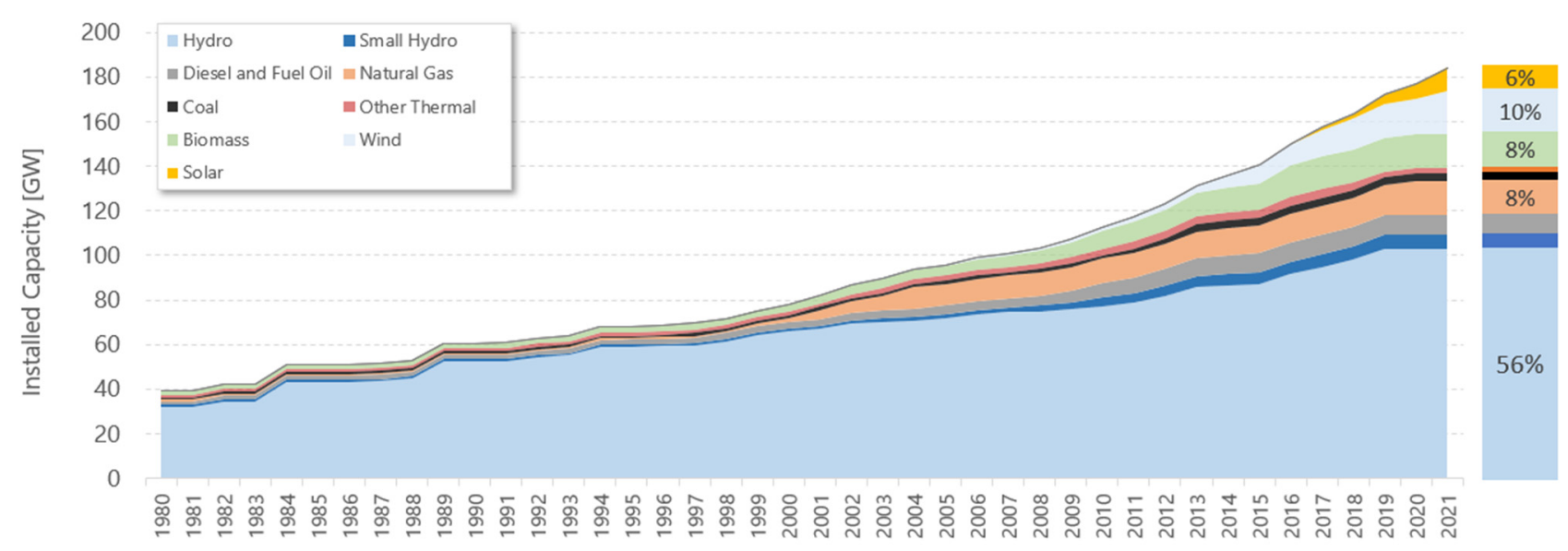

Figure 1. Installed capacity evolution in Brazilian power system (Source: Authors, utilizing data from EPE).

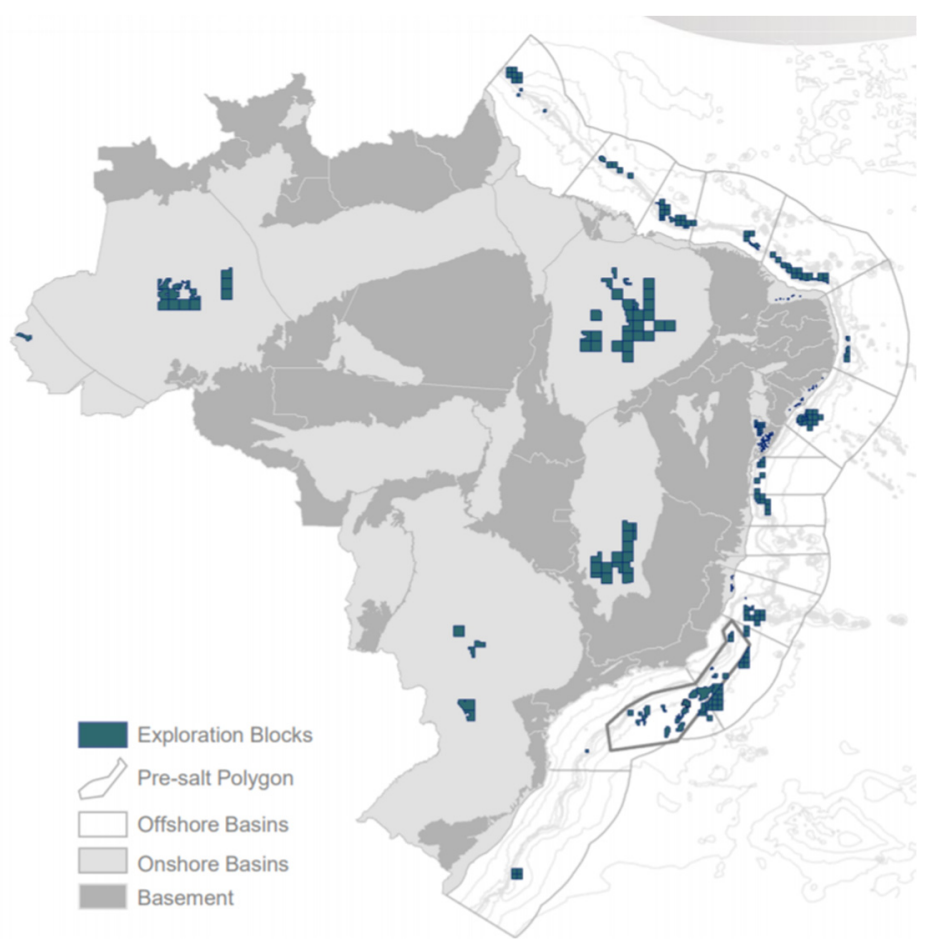

Figure 2. Brazilian oil fields map (Source: ANP).

The massive oil-gas production of these fields is expected to start sometime before 2030. Since natural gas is a byproduct of the oil production, it may be leveraged by oil production, creating an opportunity for Brazil to develop new competitive gas-fired plants to complement the VRE integration and meet its increasing load growth. Nevertheless, for the development of pre-salt oil fields, the utilization of the associated gas is required, that might be through consumption, reinjection or flaring. This problem has been addressed in past decades in [10] in Norway, that developed associated gas fields similar to those found in Brazilian coast. In terms of gas utilization, the power sector might become a relevant consumer in order to accommodate the gas production through power generation and baseload thermal dispatch, depending on its final cost. The needed flexibility in this case would be indirectly provided by increasing the hydroelectric reservoir levels, recovering the system's storage capacity and providing flexibility and ancillary services to accommodate VRE integration. The issue addressed in this technical article is to estimate maximum gas costs delivered to the power plants that still allows for its development regarding the 
construction of other alternatives. The uncertainties around the cost of pre-salt natural gas, which depend on the distance from the coast, the amount of $\mathrm{CO}_{2}$ concentration on the fields and the opportunity cost of the oil production will define the competitiveness of the gas-fired plants for new investments.

In this sense, Brazilian policymakers, energy planners and oil-gas majors (that have concessions rights of those fields) are facing a debate regarding to what extent it is economic to introduce baseload gas-fired plants from these fields and enable their exploration and production. This is a very relevant policy decision for the country and for the owner of the concession rights of these fields, which are the major oil companies: Equinor, Shell, Galp and Exxon. This question is directly connected to a more general tradeoff faced by the power sector globally to address generation expansion: should new capacity be secured based mainly on VRE, apparently cheaper in pure \$/MWh terms but that will increase the usage of existing sources (hydro, in Brazil's case) to provide security services and/or of building new costly flexible thermal plants, or should investments in baseload gas-fired plants which enable existing plants to provide flexibility to accommodate VRE integration be the choice of direction, or at least part of it?

\subsection{Objectives of This Work}

This work, then, addresses this practical research question by means of a methodology based on a multi-stage and stochastic capacity expansion model to estimate the optimal mix of baseload thermal power plants and VRE additions to the system expansion portfolio, considering their reliability contribution for the supply of peak, energy and operating (spinning) reserves. We represent the operating reserves as time-varying and dynamic requirements, endogenously defined by our proposed optimization model. This means that reserve requirements are not static, defined as, for example, a percentage of peak load, but vary per hour of the day and each hour may have different reserve requirements, sized based on renewable forecast-errors and on the portfolio of existing and candidate power plants. Our model, then, calculates the tradeoffs between baseload gas and VRE supply considering their value for these services in the system. For the sake of completeness, our model also considers a set of adequacy constraints, which represents the need of system planners to have a firm capacity margin to supply peak demand [11-13]. A case study based on a real industrial application is presented for the Brazilian power system.

\subsection{Literature Survey and Paper Contributions}

The literature on electricity and gas integration is vast. Most papers cover integration issues on the operation side [14-19]. Most of these papers discuss the representation of the gas supply and network in the electricity operations models aiming to an integrated schedule. Other papers discuss similar issues on the planning side [20-23] and the literature survey is also strong on risk management and market design [3-5,24] issues between these two industries. The literature on capacity expansion planning models is even vaster. The development of generation expansion planning in optimization process first started with [25], which considered linear programming as a tool to solve the expansion problem. [26-28] provide a detailed analysis of the generation expansion planning tools history and how they have evolved. In the most general form, the capacity expansion models minimize investment and operation costs and the incorporation of reliability constraints and security criteria, as discussed in [29-33]. This work considers the contribution value of each candidate to the criteria, which is reviewed in [33].

The development of VRE has brought new challenges for optimization tools, with requirements for a more granular representation of the timescale and a greater variability on the supply-side representation. More recently, a great effort has been made on the definition of operating reserves to couple with VRE integration for operations planning. Since the sizing of reserves depends on the renewable production, the dynamic sizing of reserves to reduce procurement's cost has gained momentum [34-37]. The authors in [34] show that the operating reserves costs might decrease by about $20 \%$ in German 
system. The same conclusions are reached by the authors of [37]. They presented a dynamic sizing method that determines the required capacity on a daily basis, using the estimated probability of facing a system imbalance during the next day. A gradual implementation of dynamic reserves in Belgium since 2020 has been decided based on the results of this study. This methodology is at the core of our work.

From generation expansion planning purposes, uncertainties have been considered in different ways: the authors of [28] focus on detailing the expansion planning regarding largescale renewable participation. Ref. [38] developed a stochastic, multistage optimization tool in order to obtain the optimal transmission and energy storage expansion. [39] solved the optimal placement of storage equipment in systems with a high penetration of wind power systems. Moreover, the integration of dynamic sizing of the spinning reserve in the generation expansion planning model was developed in [40], treating it as an endogenous variable. This is an important development that has formed the basis of the research in our work as it allows for the capacity planning model to dictate the generation expansion options that also minimizes reserves costs. This model considers the variability of the hourly differences of the production from each renewable scenario. Ref. [41] raised the importance of representing greater granularity characteristics in power system modelling, showing an underestimation of costs in the Belgian power system of up to $58 \%$ in case of neglecting the low temporal constraints [42].

Our work fits into the planning and investment sides and covers the specific application of valuing baseload gas-fired power plants in a hydro-dominated system with increasing penetration of renewables. The contributions of our work are threefold: (i) we develop a methodology to determine the breakeven gas prices that turn the baseload gas plants and renewables equivalent under the hydro-dominated system standpoint, that is, to satisfy the same set of constraints (providing equivalent economic value); (ii) for this, we utilize a capacity expansion planning model that addresses energy, peak and the endogenous definition of time-varying and dynamic operating reserves in a probabilistic way. Our model is based on multistage, multiarea, stochastic MIP problem with hourly timescale resolution with co-optimization between energy and reserves and adequacy constraints; (iii) we apply the methodology to real-life case studies for the Brazilian system, where this problem is current under discussion. To the best of our knowledge, this is the first time this type of analysis is conducted in the literature for a hydro-dominated system. With our analysis, we also expect to contribute to the discussion on how to compare renewables and gas-fired plants on the same basis, i.e., to supply the same set of system services (or "attributes") and of the value aggregated for them.

This paper is structured as follows: Section 2 provides the overview of the proposed methodology. Section 3 presents a real case study addressing this problem in Brazilian power system. Section 4 discusses the observed results from the proposed methodology. Finally, Section 5 concludes the work's observations and analysis.

\section{Methodology}

The capacity expansion problem demands the selection of the generation and transmission options to meet future power load requirements at the least possible cost. Since different resources have different characteristics, the value of each project to the system depends on how the production profile and services provision match the system needs and on the correspondent cost. The Brazilian power system has many candidate options: a large resource potential for hydro is available, as it is for wind, solar and biomass. Gas-fired plants can be an alternative, with gas sourced from cross-border pipelines, LNG or from domestic the pre-salt fields. Each option has its own characteristic: distance to load centers, transmission investment needs, flexibility, intermittency, etc.

Our goal is to calculate the value of baseload gas-fired generation against other portfolio options when integrated into the Brazilian system. This paper uses an approach founded on the gas opportunity cost calculation by the point of view of the power sector. In other words, the attractiveness in terms of installed capacity of the pre-salt power plants 
depending on their natural gas cost and the maximum gas price that the power sector is willing to pay based on the other expansion alternatives. This is represented in the following procedure:

Step 1: Start from an existing generation-transmission system configuration over a given horizon;

Step 2: Define a load growth scenario and a set of generation expansion candidates, as well as their CAPEX \& OPEX and technical characteristics;

Step 3: for a given gas price delivered at the power plant, utilize the solution strategy defined in the capacity expansion planning model explained in the next section to determine the sizing of the gas-fired plants in the system to supply the load growth.

Figure 3 depicts this procedure.

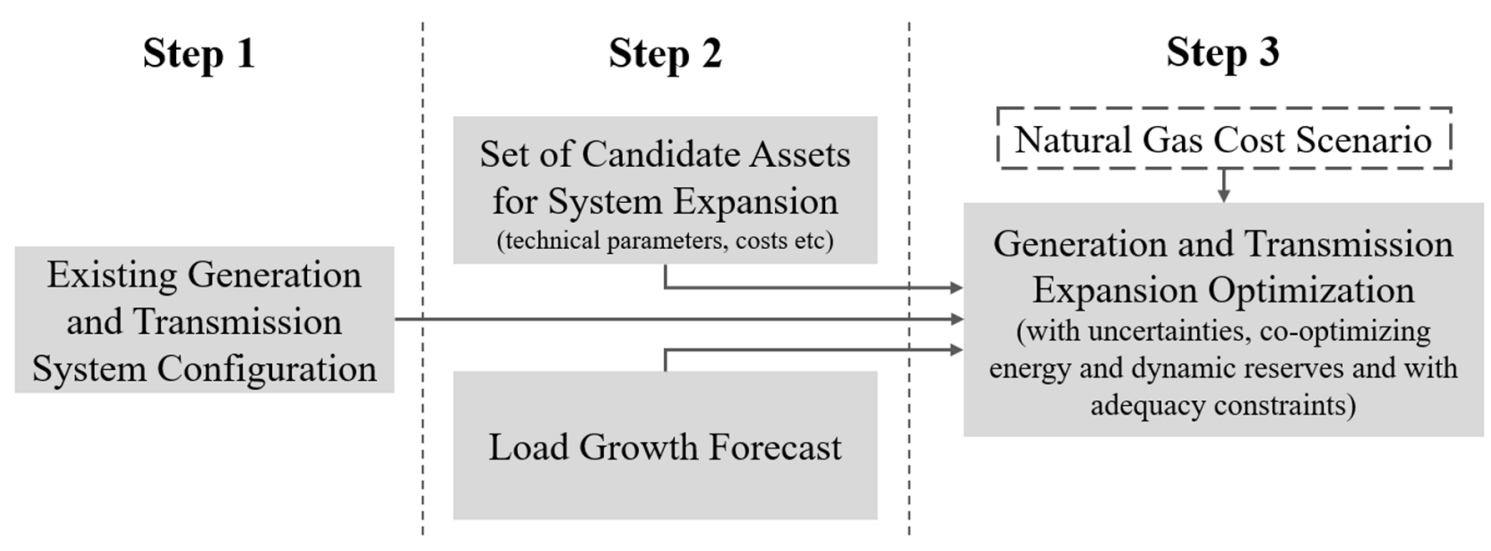

Figure 3. Main steps of the methodology (Source: Authors' elaboration).

Steps (1) to (3) can be repeated for a set of candidate gas prices for the pre-salt gas, depicting the attractiveness of the baseload power generation as a function of the natural gas price. The value that enables gas-fired plants to be selected by the optimal planning model defines how the power sector can breakeven. For gas prices higher than this value, the expansion based on greater amounts of VRE with other flexible options is more costeffective. This exercise can be repeated for different modeling features of the capacity expansion model and assess how the supply of different services affect the competitiveness of the gas-fired plants. For example, we can assess the competitiveness with respect to the energy supply and to the supply of other reliability constraints and reserves. In this paper, this exercise was conducted twice, representing different constraints in the expansion planning model.

\subsection{Solution Strategy}

For addressing the answers of the questions raised questions in this work, a generation, transmission and reserve requirements co-optimization model was developed, which aims to minimize the system total cost, represented by the sum of investment and the expected operating costs, satisfying a set reliability constraints (supply of energy, peak and endogenously-refined operating reserves) under uncertainty in water availability and wind and solar generation. This is conducted through a mixed integer programming (MIP) strategy, with hourly resolution.

Since power systems expansion planning is usually carried out over time spans of several years, some simplifying strategies are required to make its solution feasible, especially when representing the intraday operation. To do so, the current work uses some time-clustering assumptions. The first step of this process is clustering some of the months into seasons, which should be defined based on rainy and dry periods and the demand profiles. Once the seasons are defined, the representative days within each of them must be estimated, here referred to as typical days. 
This type of representation aims to reduce problem size, capturing the main characteristics within each common day in each season. The work developed in [43] uses a clustering concept to define the typical days to be used by the proposed generation expansion model. For the modelling presented in this work, two typical days were defined for each of the four seasons. The definition of the seasons was based on three-months clusters. For each season, the days were separated into two groups: weekdays and weekends. Figure 4 summarizes the discussed clustering strategy.
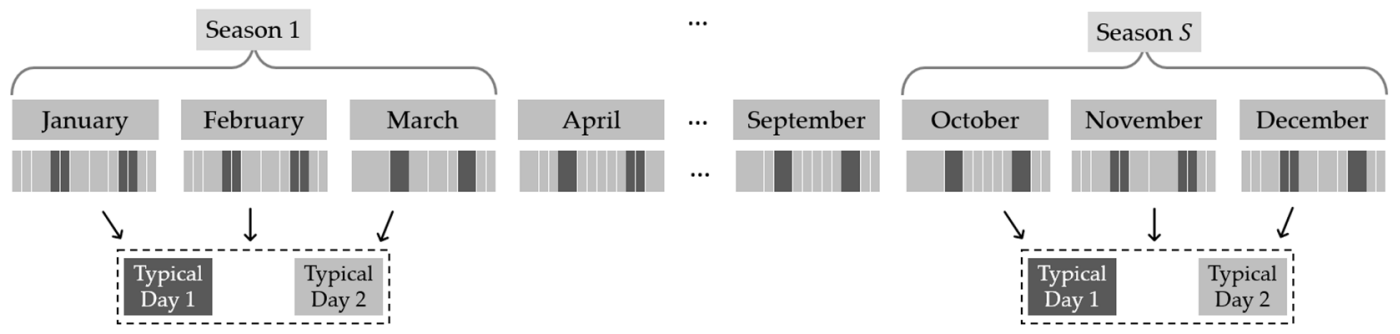

Figure 4. Example of seasons and typical days clustering strategy (Source: Authors' elaboration).

The optimization developed in this paper also contemplates the operating reserve constraints as a variable of the decision process, which will depend on the generation variability of renewable energy sources. The endogenous sizing of the spinning reserve calculation considers, for each hour of each typical day, a convex combination between the average and Conditional Value at Risk (CV@R) of the differences between the real and the expected variation between hours of the production of renewable assets. For the linear programming problem of the CV@R, we refer to [44]. Figure 5 illustrates the process of Dynamic Probabilistic Reserve (DPR) sizing scheme, similar to the ones proposed by $[34,35,40]$.

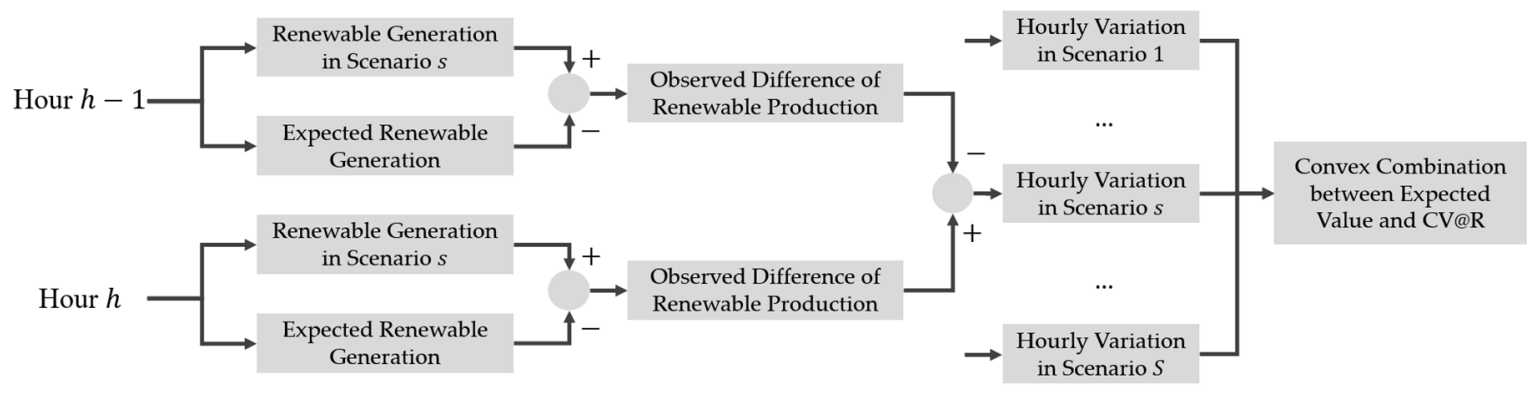

Figure 5. Dynamic Probabilistic Reserve sizing scheme (Source: Authors' elaboration).

Therefore, this approach ensures that the reserve requirements will be sized for each specific hour, considering every scenario used in optimization problem. Since the spinning reserve requirement will be different for each hour, it is also considered as dynamic, as well as probabilistic once it uses different renewable production scenarios in its sizing.

\subsection{Problem Formulation}

The optimization model used in this simulation is based on [40] and can be formulated as follows:

- Objective Function:

$$
\operatorname{Min} \sum_{k \in \mathcal{K}} I_{k} \cdot x_{k}+\sum_{s \in \mathcal{S}} p_{s} \sum_{t \in \mathcal{T}} \sum_{l \in \mathcal{L}} \beta_{l} \sum_{h}\left(\sum_{i \in \mathcal{I}} c_{i} \cdot g_{i, t, l, h, s}+\sum_{k \in \mathcal{K}_{\mathrm{i}}} c_{k} \cdot g_{k, t, l, h, s}+\mathrm{c}^{\mathrm{d}} \cdot \sum_{b \in \mathcal{B}} \sigma_{b, t, l, h, s}\right)
$$


- Load Balance:

$$
\begin{aligned}
\text { s.t. : } \quad \sum_{i \in \mathcal{J}_{b}} g_{i, b, t, l, h, s}+\sum_{k \in \mathcal{K}_{i, b}} g_{k, b, t, l, h, s}+\sum_{j \in \mathcal{J}_{b}}\left(f_{b, j, t, l, h, s}^{+}-f_{b, j, t, l, h, s}^{-}\right) \\
+\sum_{k \in \mathcal{K}_{j, b}}\left(f_{b, k, t, l, h, s}^{+}-f_{b, k, t, l, h, s}^{-}\right)+\sum_{n \in \mathcal{N}_{b}}\left(\theta_{b, n, t, l, h, s}^{+}-\theta_{b, n, t, l, h, s}^{-}\right) \\
+\sum_{k \in \mathcal{K}_{n, b}}\left(\theta_{b, k, t, l, h, s}^{+}-\theta_{b, k, t, l, h, s}^{-}\right)+\sigma_{b, t, l, h, s}=d_{b, t, l, h}, \forall b, t, l, h, s
\end{aligned}
$$

- Operative Variables Limits:

$$
\begin{gathered}
0 \leq \delta_{b, t, l, h, s} \leq d_{b, t, l, h}, \forall b, t, l, h, s \\
0 \leq g_{i, t, l, h, s}+r_{i, t, l, h, s} \leq \bar{g}_{i^{\prime}}, \forall i, b, t, l, h, s \\
g_{i} \leq g_{i, t, l, h, s}, \forall i, b, t, l, h, s \\
0 \leq f_{b, j, t, l, l, s^{\prime}}^{+} f_{b, j, t, l, h, s}^{-} \leq F_{b, j}, \forall j, b, t, l, h, s \\
0 \leq g_{k, t, l, h, s}+r_{k, t, l, h, s} \leq \bar{g}_{k} \cdot x_{k}, \forall b, t, l, h, s, \forall k \in \mathcal{K}_{i} \\
g_{k} \cdot x_{k} \leq g_{k, t, l, h, s}, \forall b, t, l, h, s, \forall k \in \mathcal{K}_{i} \\
0 \leq f_{b, j, t, l, l, s^{\prime}}^{+} f_{b, j, t, l, h, s}^{-} \leq F_{b, k} \cdot x_{k}, \forall b, t, l, h, s, \forall k \in \mathcal{K}_{j}
\end{gathered}
$$

- Ramp-up and Ramp-down Limits:

$$
\begin{gathered}
g_{k, t+1, l, h, s}-g_{k, t, l, h, s} \leq \overline{\Delta g_{i}}, \forall i, b, t, l, h, s \\
g_{k, t, l, h, s}-g_{k, t+1, l, h, s} \leq \Delta g_{i}, \forall i, b, t, l, h, s \\
r_{i, t, l, h, s} \leq \Delta g_{i}, \forall i, b, t, l, h, s
\end{gathered}
$$

- Operating Reserve and Adequacy Constraints:

$$
\begin{gathered}
\sum_{i \in \mathcal{I}_{b}} r_{i, t, l, h, s}+\sum_{k \in \mathcal{K}_{i, b}} r_{k, t, l, h, s}=R_{b, t, l, h}, \forall b, t, l, h, s \\
\underline{\Phi} \leq \sum_{i \in \mathcal{I}} \phi_{i}+\sum_{k \in\left(\mathcal{K}_{i} U \mathcal{K}_{n}\right)} \phi_{k} \cdot x_{k} \leq \bar{\Phi}
\end{gathered}
$$

- Hydro Power Plants Constraints:

$$
\begin{gathered}
v_{i, t+1, l, h, s}=v_{i, t, l, h, s}+a_{i, t, l, h, s}-\left(u_{i, t, l, h, s}+u_{i, t, l, h, s}^{\prime}\right)+\sum_{m \in \mathcal{M}}\left(u_{m, t, l, h, s}+u_{m, t, l, h, s}^{\prime}\right) \\
-\eta_{i, t, l, h, s,} \forall i, t, l, h, s \\
v_{i, T+1, l, h, s}=v_{i, 1, l, h, s}, \forall i, l, h, s \\
0 \leq u_{i, t, l, h, s} \leq \bar{u}_{i}, \forall i, t, l, h, s \\
\underline{v}_{i} \leq v_{i, t, l, h, s} \leq \bar{v}_{i}, \forall i, t, l, h, s \\
u_{i, t, l, h, s}+u_{i, t, l, h, s}^{\prime} \geq \underline{q}_{i}, \forall i, t, l, h, s \\
g_{i, t, l, h, s}=\rho_{i} \cdot u_{i, t, l, h, s}, \forall i, t, l, h, s
\end{gathered}
$$


- Energy Storage Equipment Constraints:

$$
\begin{aligned}
v_{n, t+1, l, h, s}^{b}= & \epsilon \cdot v_{n, t, l, h, s}^{b}+\mu \cdot \theta_{n . t, l, h, s}^{+}-\theta_{n, t, l, h, s^{\prime}}^{-}, \forall n, t, l, h, s \\
0 \leq & \theta_{n, t, l, h, s^{\prime}}^{+} \theta_{n, t, l, h, s}^{-} \leq \Theta_{n}, \forall n, t, l, h, s \\
& v_{n, T, l, h, s}^{b}=v_{n, 1, l, h, s}^{b}, \forall n, t, l, h, s \\
& 0 \leq v_{n, t, l, h, s}^{b} \leq \bar{v}_{n}^{b}, \forall n, t, l, h, s \\
& 0 \leq v_{n, t, l, h, s}^{b} \leq \bar{v}_{n}^{b} \cdot x_{k}, \forall k, t, l, h, s
\end{aligned}
$$

- Dynamic Probabilistic Reserve Formulation:

$$
\begin{gathered}
\hat{g}_{i, b, t, l, h}=\sum_{s \in \mathcal{S}} p_{s} \cdot g_{i, b, t, l, h, s,}, \forall i, b, t, l, h \\
\hat{g}_{k, b, t, l, h}=\sum_{s \in \mathcal{S}} p_{s} \cdot g_{k, b, t, l, l, h, s}, \forall b, t, l, h, \forall k \in \mathcal{K}_{i, r e n} \\
\delta_{b, s, t, l, h}=\sum_{i \in \mathcal{I}_{r e n}}\left(g_{i, b, s, t, l, l, h}-\hat{g}_{i, b, t, l, l, h}\right)+\sum_{k \in \mathcal{K}_{i, r e n}}\left(g_{k, b, s, t, t, l, h}-\hat{g}_{k, b, t, l, l, h}\right) \cdot x_{k}, \forall b, s, t, l, h \\
\Delta_{b, s, t, l, l, h}=\left|\delta_{s, t, l, l, h}-\delta_{s, t, l, l, h-1}\right|, \forall b, s, t, l, h \\
R_{b, t, l, h} \geq(1-\lambda) \cdot \mathbb{E}\left[\Delta_{b, s, t, l, h}\right]+\lambda \cdot C V a R_{\alpha}\left(\Delta_{b, s, t, l, h}\right)+0.05 \cdot d_{b, t, l, l, h}, \forall b, t, l, h
\end{gathered}
$$

- Binary Variables:

$$
x_{k} \in\{0,1\}, \forall k
$$

Equation (1) defines the objective function, which aims to minimize the total system cost, that contains two main parcels: the investment cost and the expected operational cost. The first parcel of the objective function formulated above comprises an investment cost decision. In this parcel, $k$ represents a candidate from the set of available candidates, $\mathcal{K}$, composed by generation candidates, $\mathcal{K}_{i}$, transmission candidates, $\mathcal{K}_{j}$, and energy storage equipment candidates, $\mathcal{K}_{n}$. For each of the candidates, there are defined the annualized investment cost, $I_{k}$. Moreover, the decision of investing in each of available candidate is based on the binary decision variable, $x_{k} \in\{0,1\}$.

The second parcel represents the expected value of the operating costs. Hence, for each scenario, $s$, in the set of simulated scenarios, $\mathcal{S}$, it is defined a probability, $p_{s}$, that multiplies the total operational cost of this scenario. The seasons are represented by $t$ and the set of seasons by $\mathcal{T}$. The typical day is defined as $l$ and the set of typical days as $\mathcal{L}$. To represent the correct duration of each typical day, the variable $\beta_{l}$ indicates the weight of the typical day in its season. The variable $g_{i, t, l, h, s}$ represents the generation of an existing power plant, $i$, in the set of all existing power plants, which is multiplied by its operative cost, $c_{i}$. Similarly, the cost of generation of each candidate is calculated by multiplying the generation, $g_{k, t, l, h, s}$ by its operative cost, $c_{k}$. Finally, the loss of load cost is represented by $c^{d}$, while $\sigma_{t, l, h, s}$ indicates the depth of loss of load at each moment.

For each bus $b$, that belongs to the group of buses, $\mathcal{B}$, the Equation (2) represents its load balance. It states that at every moment the load balance must be satisfied through generation of the assets connected in this bus, energy imports/exports, $f_{b, j, t, l, h, s^{\prime}}^{+} f_{b, j, t, l, h, s^{\prime}}^{-}$ battery charge/discharge, $\theta_{b, n, t, l, h, s^{\prime}}^{+} \theta_{b, n, t, l, h, s^{\prime}}^{-}$and load-shedding. Equation (3) limits the load shedding at each bus to its own load.

Equation (4) indicates the maximum generation capacity of an existing power plant. This constraint limits the sum of generation and reserve, $r_{i, t, l, h, s}$, that was allocated to the generation asset to its maximum generation, $\bar{g}_{i}$. It guarantees the generation asset will be able to produce the necessary energy if requested. The minimum generation of a power 
plant is defined as $g_{i}$ in Equation (5). The transmission capacity is limited by the Equation

(6) in both directions. The right-hand side of this equation is the maximum flow through the circuits $j$ that connect the bus $b$, thus represented by $F_{b, j}$. Equations (7)-(9) have the same concept as Equations (4)-(6), however for candidates. It is noteworthy to mention that by multiplying the maximum generation by the decision variable of constructing the candidate will allow for the limitation of the maximum generation to zero in case of not deciding to construct it.

The maximum ramp-up and ramp-down are represented by $\overline{\Delta g_{i}}$ and $\Delta g_{i}$, respectively,

and limit the output variation of generation assets in Equations (10) and (11). In order to accommodate the allocated spinning reserve and guarantee that the generator will be able to provide the expected production if necessary; the spinning reserve is also restrict to the ramp-up and ramp-down maximum values in Equation (12).

Equation (13) represents the operating reserve balance per bus, allowing for the allocation of the reserve to the available generators, satisfying the reserve requirements, which are dynamically defined by the variable $R_{b, t, l, h}$ that will be further explained. Equation (14) represents adequacy constraint, which allows the possibility for the system planner to exogenously incorporate minimum volumes of firm capacity requirements on top of the peak loads. This has been of increasing interest in many systems all around the globe. The contribution of each power plant to the firm capacity is represented by $\phi$ and the minimum and maximum firm capacity requirements by $\Phi, \bar{\Phi}$, respectively. The set of constraints comprised of Equations (13) and (14) reinforces the supply of operating reserves and system adequacy. Thus, hereafter, this set will be also referred to security constraints.

Equation (15) shows the water balance in each hydro reservoir. The variable $v_{i, t+1, l, h, s}$ is the reservoir level by the end of the hour $h$, while $v_{i, t, l, h, s}$ is the reservoir level on the beginning of the hour $h$. The inflow is $a_{i, t, l, l, h, s}$, the water discharged into turbines $u_{i, t, l, h, s,}$ the spilled water $u_{i, t, l, h, s}^{\prime}$ and the water losses $\eta_{i, t, l, h, s}$ (necessary to represent the irrigation and evaporation, for example). The upstream reservoirs comprise the set $\mathcal{M}$ (only those right before the analyzed reservoir), and the sum of their discharged water is added to the current reservoir.

Equation (16) associates the final volume to the initial volume, representing a steady state strategy for the reservoir in this model. Its intention is to represent a steady-state operation, in which the initial point of operation does not matter, however, the net energy balance should be zero in the study horizon. Equation (17) limits the water discharged into turbines and Equation (18) the minimum and maximum reservoir levels, which are limited respectively by $\underline{v}_{i}, \bar{v}_{i}$. Equation (19) guarantees the river flow by adding a constraint that imposes the minimum outflow from reservoir, $\underline{q}_{i}$. Finally, the generation of this power plant is related to the discharged water by Equation (20), where $\rho_{i}$ is the energy production function of this power plant. In this case, the function is defined as a constant.

The operation of batteries is represented by Equations (21)-(25). Equation (21) states the energy balance in storage equipment (similar to hydro power plants), where $v_{i, t, l, h, s}^{b}$ is the volume of the battery, $\epsilon$ represents the energy loss from one period to the other, $\theta_{n, t, l, h, s^{\prime}}^{+} \theta_{n, t, l, h, s}^{-}$mean, respectively, the charging and discharging variables and $\mu$ the energy loss in charging process.

Equation (22) limits the range of charging and discharging variables to the maximum output capacity of the battery, $\Theta_{n}$. Equation (23) equalizes the initial volume of the final volume of the storage equipment. Finally, Equations (24) and (25) limit the volume of the batteries (both existing and candidates) to the maximum volume, $\bar{v}^{b}{ }_{n}$.

Finally, the DPR representation in optimization problem is defined through Equations (26)-(30). The Equations (26) and (27) are used to calculate the expected generation, $\hat{g}$, of the existing and candidate renewable assets, respectively. Equation (28), then, calculates the difference between the observed renewable generation for each scenario to the expected generation. It is noteworthy to mention that, in case the renewable candidate is not selected, its contribution to the increment of this variable in null. Hence, the Equation (29) is used to 
calculate the absolute difference of the variation of the total renewable production between hours, $\Delta_{b, s, t, l, h}$.

Since this optimization problem considers the convex combination of expected value and conditional value at risk of hourly difference variability to calculate the operations reserve requirement of the system, it is necessary to represent the CV@R as a linear programming problem in order to integrate it into the original problem. Therefore, we refer the linear formulation of the CV@R to [44]. Finally, the final spinning reserve requirement is defined in Equation (30). It is composed by the convex combination of the expected value and CV@R of the $\Delta_{b, s, t, l, h}$ added to the $5 \%$ of the load. In this equation, the $\lambda$ represents the convex combination parameters, which provides the CV@R weight in convex combination function and $\alpha$ is the $\mathrm{CV} @ \mathrm{R}$ parameter corresponding to the percentile of the scenarios.

Based on this formulation, this model is able to capture the intermittency and correlation associated to VRE, since it represents the generation of power plants in hourly steps. Furthermore, due to the usual daily pattern of VRE, the spinning reserve requirements is also defined in hourly steps through this model.

\subsection{Solution Approach}

Our model is formulated as a mixed-integer linear program (MILP) and solved by commercially available optimization solvers.

\section{Case Study: Assessing the Competitiveness of Base-Load Gas Generation from Pre-salt Gas Fields Assumptions}

For the purpose of this paper, the natural gas opportunity cost of pre-salt projects is obtained through the calculation of the generation and transmission expansion optimization in order to supply the load growth for the 2024 to 2030 period. The expansion results are presented for the year 2030. Additionally, for the sake of simplicity, we represent this opportunity cost as a flat number along the year. Table 1 depicts the system's capacity breakdown per technology for the 2024 configuration of the study.

Table 1. Existing installed capacity per technology in 2024 (Source: EPE).

\begin{tabular}{cc}
\hline Technology & Existing Installed Capacity (GW) \\
\hline Hydro & 119.0 \\
Biomass & 18.2 \\
Wind & 28.5 \\
Solar & 9.7 \\
Diesel & 0.0 \\
Nuclear & 3.4 \\
Natural Gas & 27.2 \\
Fuel Oil & 1.2 \\
Coal & 3.4 \\
\hline
\end{tabular}

The yearly average load consumption and yearly load peak projected for 2030 are, respectively, 1149 TWh and $174.5 \mathrm{GW}$. One can notice that the installed capacity of 2024 $(211 \mathrm{GW})$ is much greater than the average energy demand of 2030 (131 average GW). This is typical from hydro systems, designed to supply load under very adverse hydrological conditions (dry seasons), which do not occur often. Hence, it is natural to have an excess capacity with respect to the energy load (the energy supply is limited by hydrological conditions). Renewables compound this challenge with their own intermittency, thus requesting more spare capacity to make up for the reserves.

For the purpose of this analysis, this model considers stochastic analysis for the energy production of renewable power plants (hydro, solar and wind). The hydro availability was modelled as periodic autoregressive model (PAR) [45], using the available monthly historical records from 1931 to 2018 from the Brazilian system operator dataset. For renewable 
power plants, the scenarios were created using a Bayesian network approach [46], which were correlated to the hydrological inflows in order to capture the real characteristics of the resources' availability. These renewable scenarios are considered in hourly timescale, which grants to capture the effect of hourly constraints in system expansion planning.

Table 2 provides the capital expenditure (CAPEX) and operational expenditure (OPEX) costs for each candidate source used for this simulation, which is an input for the optimization model to economic evaluate the new capacity sources and build the least-cost energy portfolio, satisfying the adequacy requirements.

Table 2. CAPEX and OPEX assumptions (Source: PSR Energy Consulting and Analytics, using data from IRENA and IEA).

\begin{tabular}{ccc}
\hline Technology & $\begin{array}{c}\text { CAPEX } \\
\text { (USD/kW) }\end{array}$ & $\begin{array}{c}\text { OPEX } \\
\text { (USD/kW·Year) }\end{array}$ \\
\hline Wind & 1385 & 28 \\
Solar & 1108 & 14 \\
Biomass & 1108 & 25 \\
Open-cycle gas turbine & 720 & 75 \\
Close-cycle gas turbine (pre-salt) & 831 & 47 \\
Close-cycle gas turbine (LNG) & 942 & 47 \\
\hline
\end{tabular}

Besides the investment costs, it is necessary to calculate the operating variable cost for those indicative TPP projects. Table 3 presents the assumptions for the operating variable cost and flexibility of each TPP project, considering the gas price of 3 USD/MMBtu for the pre-salt gas fields as an example.

Table 3. Operating cost assumptions for candidates' gas-fired thermal powerplants (Source: PSR Energy Consulting and Analytics, using data from IRENA and IEA).

\begin{tabular}{lcccc}
\hline \multicolumn{1}{c}{ Candidate } & $\begin{array}{c}\text { Gas Price } \\
\text { (USD/MMBtu) }\end{array}$ & $\begin{array}{c}\text { Heat Rate } \\
\text { (MMBtu/MWh) }\end{array}$ & $\begin{array}{c}\text { Operating Cost }^{2} \\
\text { (USD/MWh) }\end{array}$ & $\begin{array}{c}\text { Flexibility }^{2} \\
\text { Open-cycle gas turbine }\end{array}$ \\
Combined-cycle gas turbine (pre-salt) & 12.60 & 8.50 & 138.50 & Flexible \\
Combined-cycle gas turbine (LNG) & 3.00 & 6.00 & 25.05 & Baseload \\
\hline
\end{tabular}

${ }^{1}$ With taxes and charges of the gas sector. ${ }^{2}$ Includes variable O\&M cost and taxes and charges of the power sector. ${ }^{3}$ Considers 2 USD/MMBtu from liquefaction, 1 USD/MMBtu form shipping, 1 USD/MMBtu for regasification and $1.15 \cdot$ Henry Hub.

\section{Results and Discussion}

The value of the pre-salt gas fired plants was assessed for two different simulations: (i) competitiveness based only on the supply of energy needs in the capacity planning model and (ii) analysis also considering the need to supply reliability constraints (dynamic operating reserves and peak), in addition to the energy demand.

The CPU time for each simulation ranged from $656 \mathrm{~s}$ to $23,029 \mathrm{~s}$, taking $7416 \mathrm{~s}$ on average, since this optimization model is based on MIP, which depends on heuristics and convergence methods to obtain its solution.

\subsection{Value of Pre-Salt Natural Gas Power Plants: Energy-Only Cost Analysis}

In the first analysis, the model does not consider the set of constraints defined in Equations (13) and (14) on peak and operating reserves in the model formulation. Consequently, the model calculates an optimal expansion plan based on a pure-economical tradeoff between building new capacity and using the existing system to meet the energy demand growth (with the purpose to reduce investments plus operative costs). Since transmission is also considered, there is another tradeoff (not explored in this paper) that is to build candidates close to the load center or to invest in new technology far away from it, which would require the construction of new transmission lines 
Figure 6 presents the amount of installed capacity for pre-salt gas-fired projects for a range of pre-salt gas prices, including all taxes, sector charges and gas distribution cost.

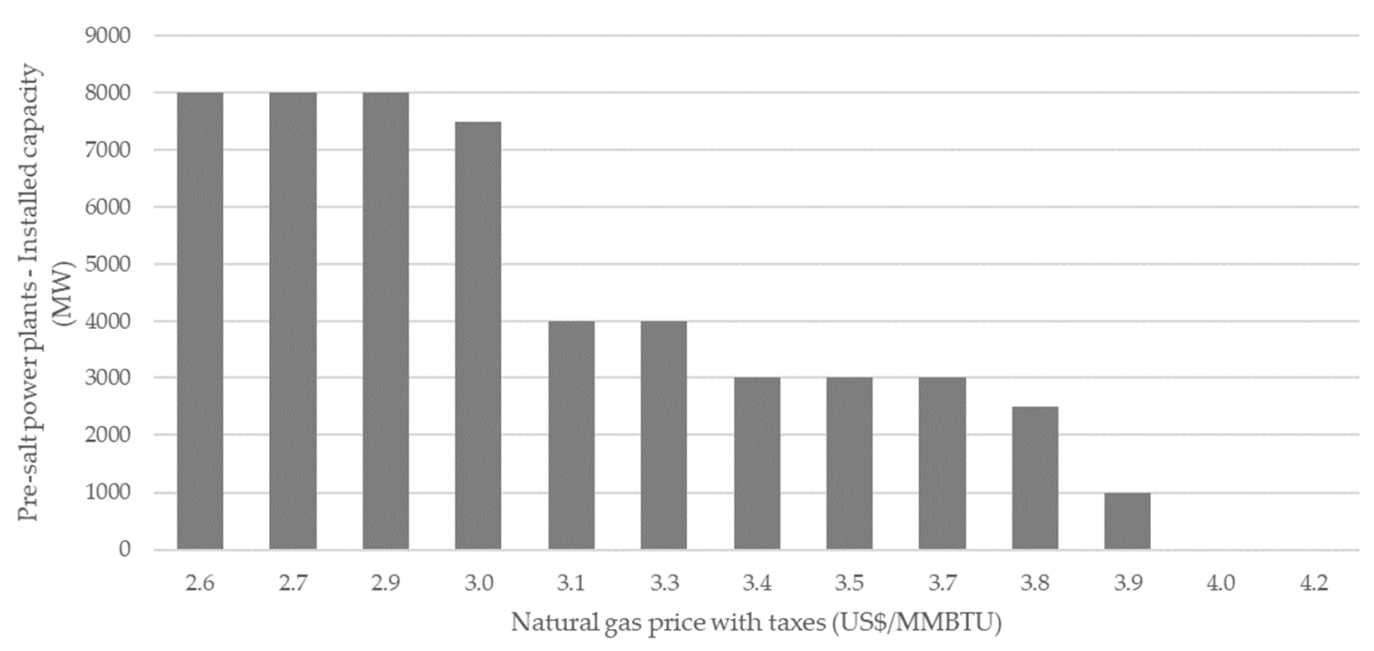

Figure 6. Additions of pre-salt natural gas power plants for different pre-salt natural gas prices.

As shown, the maximum price for base-loaded pre-salt natural gas that can charged to the power system and that would enable the economic construction of any volume is 3.9 USD/MMBTU. As expected, the reduction in natural gas price increases the attractiveness of these projects, as their volume is increased. While the decision for 3.9 USD/MMBTU gas price is to install $1 \mathrm{GW}$ of those pre-salt power plants, the $3.3 \mathrm{USD} / \mathrm{MMBTU}$ and $2.9 \mathrm{USD} / \mathrm{MMBTU}$ gas prices increase this amount to $4 \mathrm{GW}$ and $8 \mathrm{GW}$-reaching approximately $40 \mathrm{Mm}^{3}$ / day of gas consumption in total.

Since pre-salt projects are only evaluated by their energy production, it is noticeable that their main competitors were renewable sources. The increment in baseload gas-fired plants implies a in reduction in other alternatives, as it is possible to observe in Figure 7 , where the total VRE capacity is presented. Figure 7 shows total installed capacity for non-conventional renewable sources (which means solar, wind and biomass) considering different pre-salt natural gas prices.

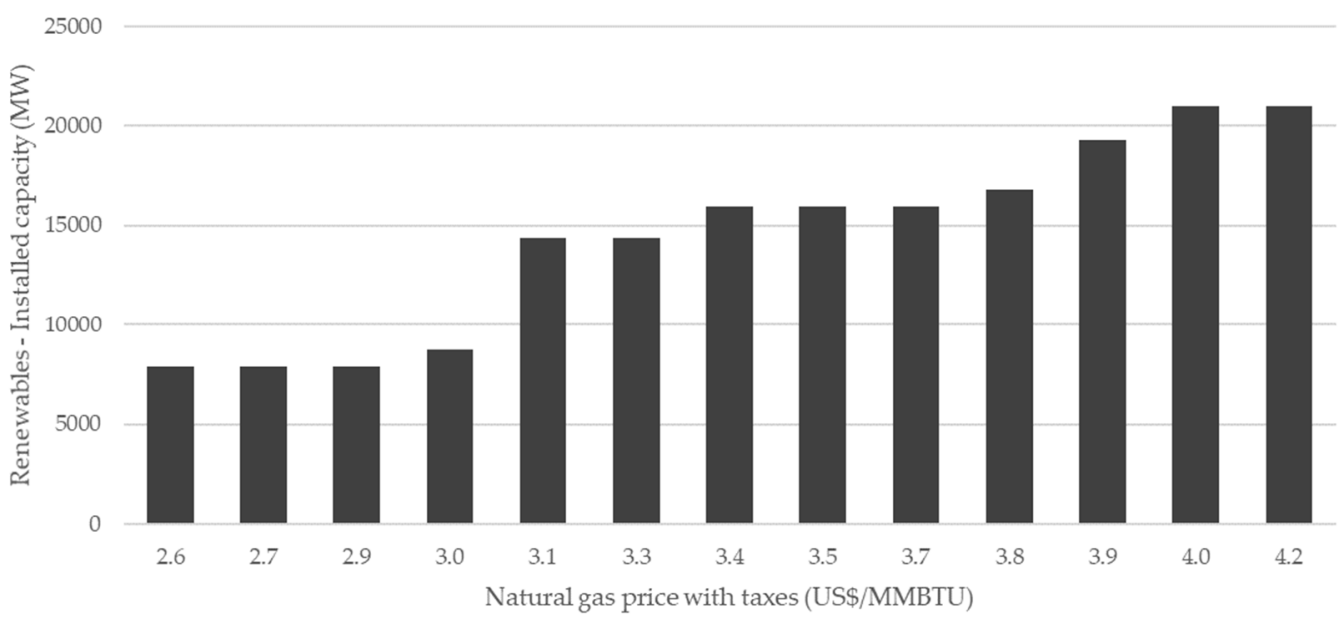

Figure 7. Additions of VRE power plants for different pre-salt natural gas prices.

For pre-salt natural gas price of 2.9 USD/MMBTU, the total renewable capacity expansion is about $8 \mathrm{GW}$. If the natural gas price were $3.7 \mathrm{USD} / \mathrm{MMBTU}$, the total renewable expansion is duplicated $(16 \mathrm{GW})$. After 4.0 USD/MMBTU, the natural gas price does not 
affect the system expansion since the pre-salt power plants would not be competitive anymore.

Accordingly, as expensive pre-salt natural gas is, more competitive non-conventional renewable sources are. It should be noted, however, that in terms of installed capacity, the displacement of pre-salt power plants by renewable projects would not be equal due to the differences between their dispatch factors.

Another important result of this model is the total system cost, which incorporates the investment and operating costs. For propose of this paper, the annualized total system cost was presented a range of pre-salt natural gas prices in Figure 8. Noticeably, the system increases its total cost accordingly to the growing profile of the pre-salt natural gas price, until the cost in which these baseload powerplants are not economical interesting to the power sector.

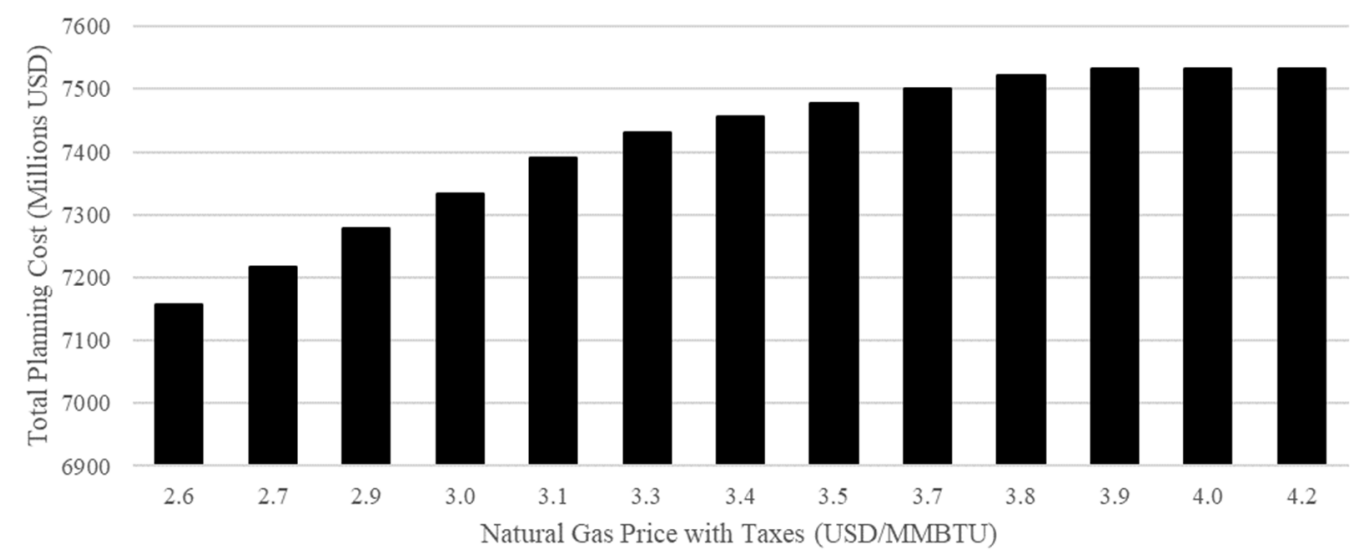

Figure 8. Total cost (sum of operating and investment) for different pre-salt natural gas prices—Energy analysis.

It is important to highlight that since part of the renewable projects represents wind farms, which are mainly from Northeast region, the optimization model has also considered transmission system expansion reinforcements in its results, so each expansion includes the transmission cost in its tradeoff.

\subsection{Pre-Salt Natural Gas Breakeven Price-Considering Security and Adequacy Constraints}

This section presents results of simulations considering Equations (13) and (14), which are dynamic operating reserves and firm capacity constraints. In this alternative scenario, the optimization model needs to cope with those constraints, so demand growth is not the only driver for system expansion. The operating reserve requirements are dynamically and endogenously defined by the optimization model itself for each model run, that determines a new supply expansion scenario for each gas price hypothesis. The representation of the adequacy constraint (Equation (14) is, however, trickier. Each generation candidate has a different firm contribution for capacity, and it beyond the scope of this work to define their calculation, which is carried out in Brazil by the Ministry of Energy supported by the Energy Planning Company. All of the resources contribute in one way or the other for firm capacity. The typical values for the Brazilian power system are described below:

The firm capacity contribution of each candidate is defined in Table 4 .

We understand these constraints are exogenously defined and may be considered as rather arbitrary and determinant to influence the results. This is true, however, our practical work shows that system planners have had great interest for this type of representation in the planning models. However, inn our runs, these constraints were not binding.

Figure 9 presents the total installed capacity of gas-fired TPPs using pre-salt natural gas for a range of gas prices. 
Table 4. Firm Capacity Contribution of each candidate.

\begin{tabular}{lcc}
\hline \multicolumn{1}{c}{ Technology } & $\begin{array}{c}\text { Capacity } \\
\text { MW }\end{array}$ & $\begin{array}{c}\text { De-rating Factor for Firm } \\
\text { Capacity } \\
\text { \% Available Capacity }\end{array}$ \\
\hline Wind & 100 & $45 \%$ \\
Solar & 100 & $29 \%$ \\
Biomass & 100 & $55 \%$ \\
Open-cycle gas turbine & 200 & $95 \%$ \\
Close-cycle gas turbine (pre-salt) & 500 & $95 \%$ \\
Close-cycle gas turbine (LNG) & 500 & $95 \%$ \\
\hline
\end{tabular}

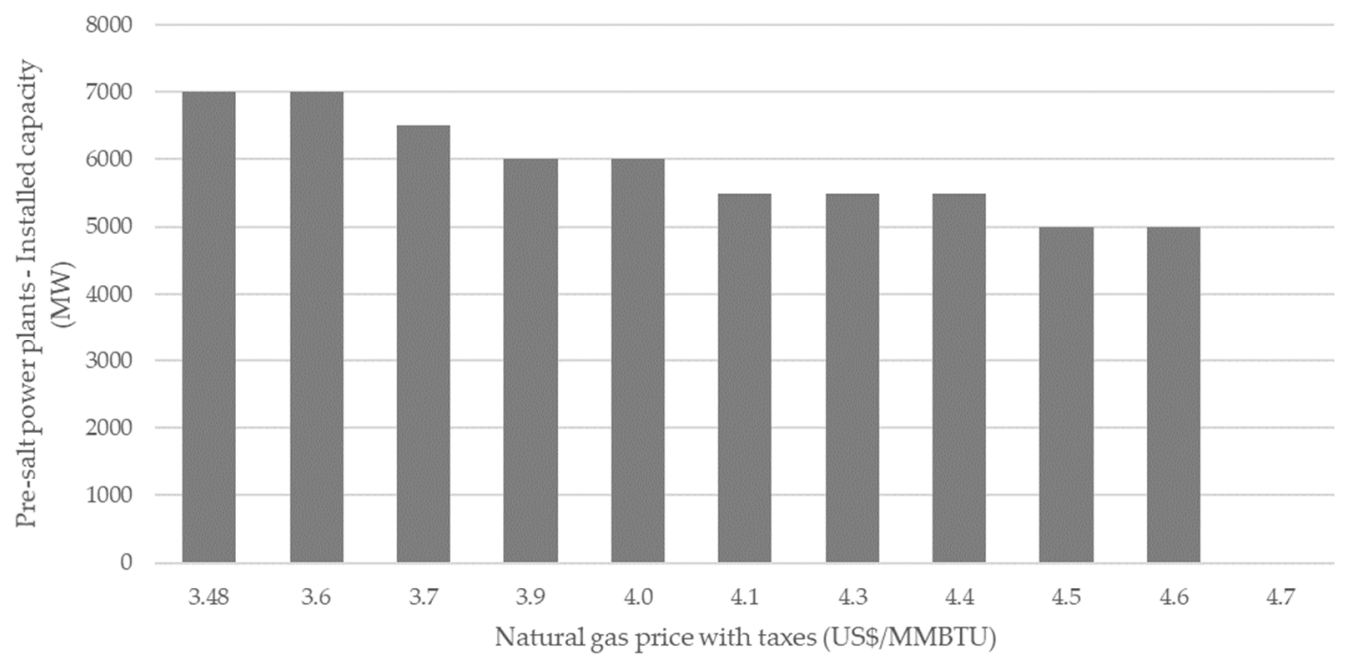

Figure 9. Additions of pre-salt power plants for a range of prices when reliability constraints are considered.

For this simulation, the breakeven price increases from 3.9 to 4.6 USD/MMBTU. In order to have at least $6 \mathrm{GW}$ of new projects (an equivalent consumption of $30 \mathrm{Mm}^{3}$ of natural gas per day), natural gas price must be lower than $4.0 \mathrm{USD} / \mathrm{MMBTU}$. For a natural gas price of $3.5 \mathrm{USD} / \mathrm{MMBTU}$, the added capacity grows from $3 \mathrm{GW}$ in only energy evaluation analysis to $7 \mathrm{GW}$ in the security-constrained simulation.

With a gas price higher than $4.6 \mathrm{USD} / \mathrm{MMBTU}$, pre-salt is replaced by $2.2 \mathrm{GW}$ of open cycle natural gas and $1 \mathrm{GW}$ of TPPs using LNG.

Noticeably, the attractiveness of these thermal plants grows substantially due to three main reasons:

1. TPPs contribute for operating reserve (due to its small flexible portion) and firm capacity requirements;

2. The growth of VRE increases the operating reserve requirements;

3. The optimal volume of capacity additions of baseload dispatch increases the hydro storage levels, thus enabling hydro plants to supply, in a cost-effective way, the operating reserves dynamically defined. An interesting discussion-but out of the scope of this paper-is how to share the benefits associated to the reserves provision between hydro ("executers") and the base load gas plants ("enablers").

Figure 10 illustrates the installed capacity of VRE for different pre-salt natural gas prices. 


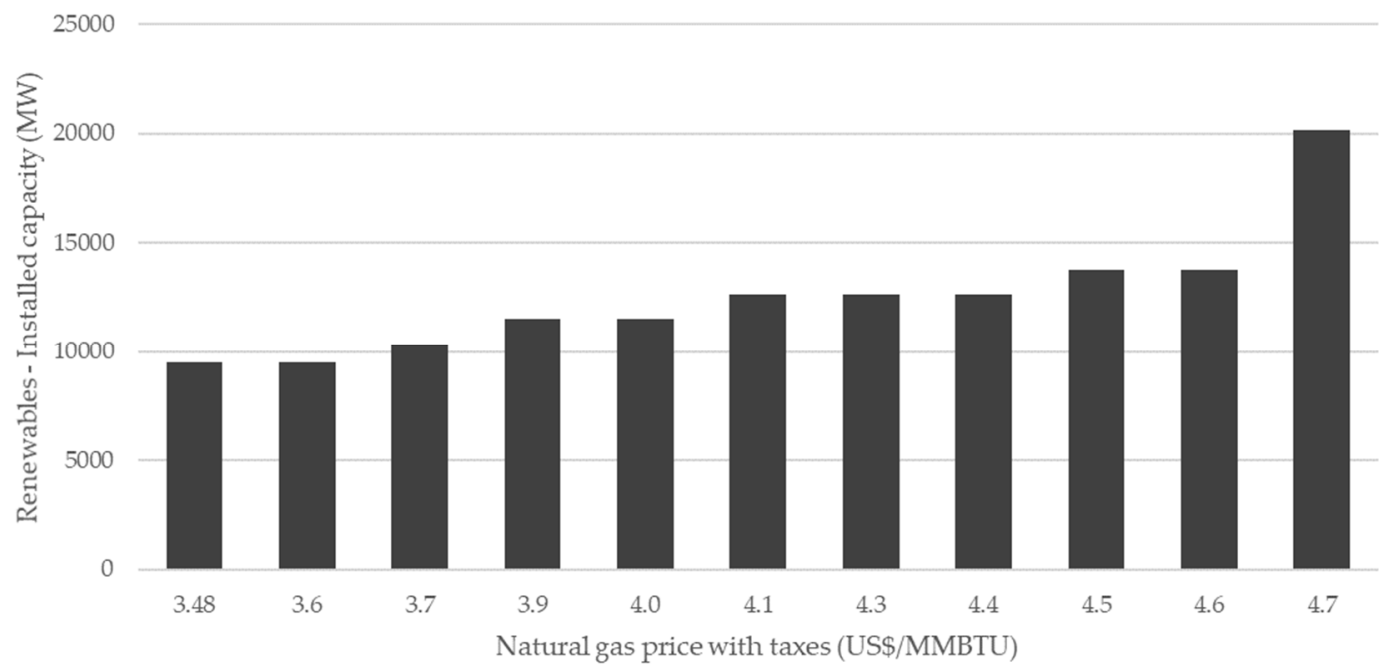

Figure 10. Addition of VRE power plants for a range of different gas prices when reliability constraints are considered.

Noticeably, the total amount of VRE reduces drastically when compared to the energy simulation, which is a consequence of their low contribution to firm capacity and increasing of spinning reserve requirements. Another consequence of both constraints is the need of other back-up sources, such as open cycle thermopower plants, to bring more flexibility to the system.

The total system cost is presented in Figure 11. Again, the growing cost of the natural gas for the power sector results in higher total cost. Besides that, the breakeven price for the attractiveness of the baseload thermopower in the Brazilian power system entailed a drastic increase in total investment cost.

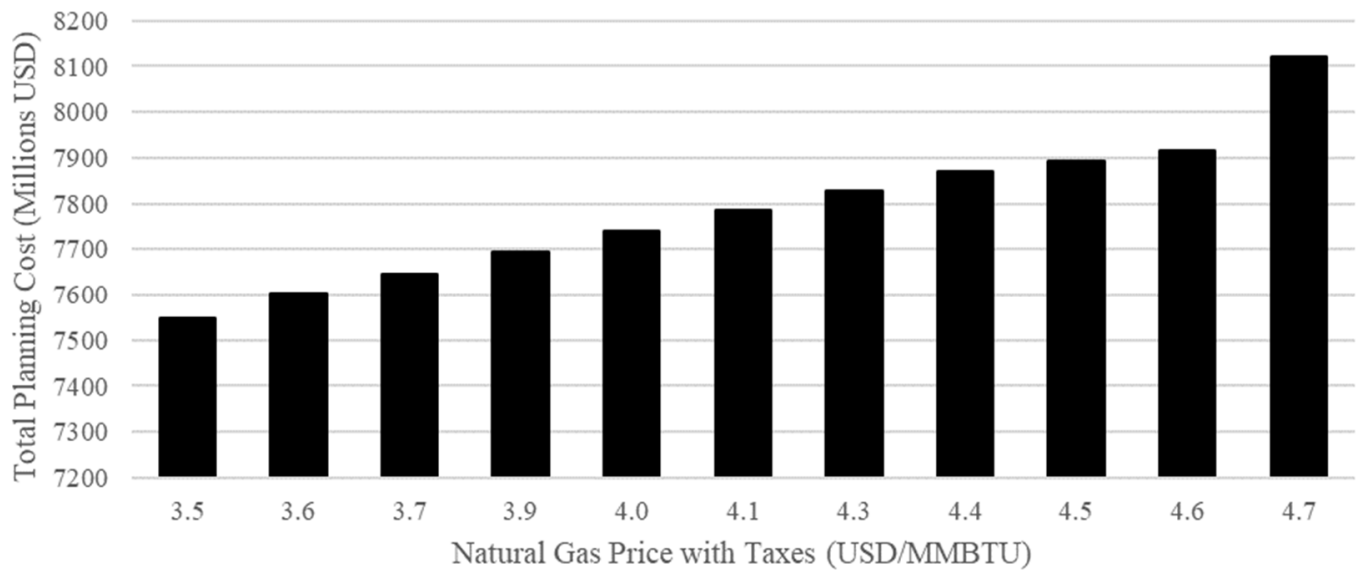

Figure 11. Total cost (sum of operating and investment) for different pre-salt natural gas prices—Reliability constraints analysis.

\section{Conclusions}

This paper presented a methodology based on a multi-stage and stochastic capacity expansion planning model to determine the competitiveness of a given technology against an existing system considering its reliability contribution, for peak, energy, and ancillary services. Our work applies this methodology to calculate the tradeoffs between base-loaded gas supply and VRE supply considering their value for these adequacy and operating services to the system. This allows for a comparison between the integration costs of these technologies on the same basis, thus helping policymakers to better decide on the best way to integrate the gas resources in an electricity industry which is increasingly renewable. 
A case study based on a real industrial application is presented for the Brazilian power system.

Our results were expressed in terms of the maximum gas price the power system is willing to pay to integrate MW from base-loaded gas plants. When applying our methodology for the Brazilian system, we show that if adequacy constraints are represented and enforced in the probabilistic planning model a maximum gas price of 4.6 USD/MMBTU (CIF) still makes base-loaded gas plants competitive. If adequacy and operating constraints are not represented, the maximum gas price becomes 3.9 USD/MMBTU. Therefore, it is possible to say that the value of the adequacy and operating services-in addition to the value of energy production-provided by baseload gas plants (such as those from the pre-salt oil and gas fields) is approximately 0.7 USD/MMBTU.

The approach proposed by this work can be used to assess the value of other technologies, as we did with the gas-fired generation, and for other power systems, not exclusively the hydro-dominated ones. The main principle is simple: factor in the planning model constraints that represent planning and operation needs and use a planning framework to assess their value by different technologies.

Furthermore, this paper did not explore many other issues that are relevant to the discussion, such as who benefits from the reserve provision of the integration of the gas-fired plants and renewables, the reserve costs and allocation costs between market participants. These remain topics for future work.

Author Contributions: Conceptualization, L.B. and B.B.; methodology, B.B., F.N.; software, F.N.; validation, F.N., B.B.; formal analysis, L.B., B.B.; investigation, L.B., F.N., B.B.; resources, PSR Energy Consulting and Analytics; data curation, F.N.; writing — original draft preparation, F.N., B.B.; writingreview and editing, L.B.; supervision, B.B.; project administration, B.B.; funding acquisition, PSR Energy Consulting and Analytics. All authors have read and agreed to the published version of the manuscript.

Funding: This research received no external funding.

Institutional Review Board Statement: Not applicable.

Informed Consent Statement: Not applicable.

Conflicts of Interest: The authors declare no conflict of interest.

\section{Nomenclature}

$\begin{array}{lll}a & \text { Water inflow } & {\left[\mathrm{m}^{3}\right]} \\ b \in \mathcal{B} & \text { Bus index } & {[\$ / \mathrm{MWh}]} \\ c & \text { Operative cost } & {[\$ / \mathrm{MWh}]} \\ c^{d} & \text { Loss of load cost } & {[\mathrm{MWh}]} \\ f^{+}, f^{-} & \text {Energy imports/exports } & {[\mathrm{MWh}]} \\ F & \text { Maximum energy transfer } & {[\mathrm{MWh}]} \\ g & \text { Power generation } & {[\mathrm{MWh}]} \\ \bar{g}, \underline{g} & \text { Maximum/minimum generation } & {[\mathrm{MWh}]} \\ \hat{g} & \text { Expected generation } & \\ h & \text { Hour index } & {[\$]} \\ i & \text { Existing power plant index } & \\ I_{k} & \text { Annualized investment cost } & \\ k \in \mathcal{K} & \text { Candidate index } & \\ \mathcal{K}=\left\{\mathcal{K}_{i}, \mathcal{K}_{j}, \mathcal{K}_{n}\right\} & \text { Set of candidates for generation, } \\ & \text { transmission and energy storage } & \\ l \in \mathcal{L} & \text { equipment } & {[\%]} \\ \mathcal{M} & \text { Typical day index } & \\ p_{s} & \text { Set of upstream reservoirs } & \end{array}$




\begin{tabular}{|c|c|c|}
\hline$q$ & Minimum outflow from reservoir & {$\left[\mathrm{m}^{3}\right]$} \\
\hline $\bar{r}$ & Power reserve & {$[\mathrm{MWh}]$} \\
\hline$R$ & Dynamically reserve requirements & [MWh] \\
\hline$s \in \mathcal{S}$ & Scenario index & \\
\hline$t \in \mathcal{T}$ & Seasons index & \\
\hline$u$ & Water discharged into the turbines & {$\left[\mathrm{m}^{3}\right]$} \\
\hline$u^{\prime}$ & Water spillage & {$\left[\mathrm{m}^{3}\right]$} \\
\hline$\underline{v}, \bar{v}$ & Maximum/minimum reservoir levels & {$\left[\mathrm{hm}^{3}\right]$} \\
\hline$v_{t}, v_{t+1}$ & $\begin{array}{l}\text { Reservoir level by the beginning/ } \\
\text { end of the period }\end{array}$ & {$\left[\mathrm{hm}^{3}\right]$} \\
\hline$v^{b}$ & Volume of the storage equipment & {$[\mathrm{MWh}]$} \\
\hline $\bar{v}^{b}$ & Maximum storage equipment volume & {$[\mathrm{MWh}]$} \\
\hline$x_{k} \in\{0,1\}$ & Decision of investing in a candidate & \\
\hline$\alpha$ & Percentile of the scenarios & \\
\hline$\beta_{l}$ & Weight of the typical day in its season & {$[\%]$} \\
\hline$\Delta$ & $\begin{array}{l}\text { Absolute difference of the variation } \\
\text { of the total renewable production } \\
\text { between hours stages }\end{array}$ & {$[\mathrm{MWh}]$} \\
\hline$\overline{\Delta g}, \Delta g$ & Maximum ramp-up/ramp-down & [MWh] \\
\hline$\epsilon$ & Stage energy loss & {$[\mathrm{MWh}]$} \\
\hline$\eta$ & Water losses & {$\left[\mathrm{m}^{3}\right]$} \\
\hline$\theta^{+}, \theta^{-}$ & Battery charge/discharge & {$[\mathrm{MWh}]$} \\
\hline$\Theta$ & Maximum output capacity & {$[\mathrm{MWh}]$} \\
\hline$\lambda \in[0,1]$ & Convex combination parameter & \\
\hline$\mu$ & Energy loss in charging process & {$[\mathrm{MWh}]$} \\
\hline$\rho$ & Energy production function & {$\left[\mathrm{MWh} /\left(\mathrm{m}^{3}\right)\right]$} \\
\hline$\sigma$ & Depth of loss of load & {$[\mathrm{MWh}]$} \\
\hline$\phi$ & Firm capacity & {$[\mathrm{MWh}]$} \\
\hline $\bar{\Phi}, \underline{\Phi}$ & $\begin{array}{l}\text { Maximum/minimum firm capacity } \\
\text { requirements }\end{array}$ & {$[\mathrm{MW}]$} \\
\hline
\end{tabular}

\section{References}

1. Barroso, L.A.; Rudnick, H.; Mocarquer, S.; Kelman, R.; Bezerra, B. LNG in South America: The markets, the prices and the security of supply. In Proceedings of the IEEE Power and Energy Society General Meeting: Conversion and Delivery of Electrical Energy in the 21st Century, PES, Pittsburgh, PA, USA, 20-24 July 2008.

2. Bezerra, B.; Barroso, L.A.; Kelman, R.; Flach, B.; Latorre, M.; Campodonico, N.; Pereira, M. Integrated Electricity-Gas Operations Planning in Long-term Hydroscheduling Based on Stochastic Models. In Hanbook of Power Systems I, Energy Systems; Springer: Berlin/Heidelberg, Germany, 2010; Volume 1, pp. 3-32.

3. Chabar, R.M.; Barroso, L.A.; Granville, S.; Pereira, M.V.; Iliadis, N. Optimization of Fuel Contract Management and Maintenance Scheduling for Thermal Plants in Hydro-Based Power Systems. In Proceedings of the Powergen Europe, Conference \& Exhibition, Milan, Italy, 28-30 June 2005.

4. Street, A.; Barroso, L.A.; Chabar, R.; Mendes, A.T.S.; Pereira, M.V. Pricing Flexible Natural Gas Supply Contracts under Uncertainty in Hydrothermal Markets. IEEE Trans. Power Syst. 2008, 23, 1009-1017. [CrossRef]

5. Barroso, L.A.; Flach, B.; Kelman, R.; Bezerra, B.; Binato, S.; Bressane, J.M.; Pereira, M.V. Integrated gas-electricity adequacy planning in Brazil: Technical and economical aspects. In Proceedings of the IEEE Power Engineering Society General Meeting, San Francisco, CA, USA, 16 June 2005.

6. IRENA. Renewable Energy Auctions: Status and Trends Beyond Price; International Renewable Energy Agency: Abu Dhabi, United Arab Emirates, 2019.

7. Porrua, F.; Bezerra, B.; Barroso, L.A.; Lino, P.; Ralston, F.; Pereira, M. Wind power insertion through energy auctions in Brazil. In Proceedings of the IEEE PES General Meeting, Minneapolis, MN, USA, 25-29 July 2010.

8. Bezerra, B.; Barroso, L.A.; Brito, M.; Porrua, F.; Flach, B.; Pereira, M.V. Measuring the hydroelectric regularization capacity of the Brazilian hydrothermal system. In Proceedings of the IEEE PES General Meeting, Minneapolis, MN, USA, 25-29 July 2010; pp. 1-7.

9. De Marreco, J.M.; Carpio, L.G.T. Flexibility valuation in the Brazilian power system: A real options approach. Energy Policy 2006, 34, 3749-3756. [CrossRef]

10. Hinderaker, L.; Njaa, S. Utilization of associated petroleum gas (APG)—The Norwegian experience. In Proceedings of the Society of Petroleum Engineers-SPE Russian Oil and Gas Technical Conference and Exhibition, Moscow, Russia, 26 October 2010; Volume 2, pp. 837-848. 
11. Crespo, L. STE Plants: Beyond Dispatchability Firmness of Supply and Integration with VRE. Energy Procedia 2015, 69, 1241-1248. [CrossRef]

12. Pérez-Arriaga, I. Security of electricity supply in Europe in a short, medium and long-term perspective. Eur. Rev. Energy Mark. 2007, 2, 1-28.

13. Faria, E.; Barroso, L.A.; Kelman, R.; Granville, S.; Pereira, M.V. Allocation of Firm-Energy Rights among Hydro agents using Cooperative Game Theory: An Aumann-Shapley approach. IEEE Trans. Power Syst. 2009, 24, 541-551. [CrossRef]

14. Unsihuay, C.; Lima, J.W.M.; De Souza, A.C.Z. Modeling the integrated natural gas and electricity optimal power flow. In Proceedings of the IEEE Power Society General Meeting, Tampa, FL, USA, 24-28 June 2007; pp. 1-7.

15. Unsihuay-Vila, C.; Marangon-Lima, J.W.; De Souza, A.C.Z.; Perez-Arriaga, I.J.; Balestrassi, P.P. A model to long-term, multiarea, multistage, and integrated expansion planning of electricity and natural gas systems. IEEE Trans. Power Syst. 2010, 25, 1154-1168. [CrossRef]

16. De Mello, O.D.; Ohishi, T. An integrated dispatch model of gas supply and thermoelectric systems. In Proceedings of the 15th Power Systems Computation Conference 2005, Liege, Belgium, 22-26 August 2005.

17. He, C.; Wu, L.; Liu, T.; Shahidehpour, M. Robust Co-Optimization Scheduling of Electricity and Natural Gas Systems via ADMM. IEEE Trans. Sustain. Energy 2017, 8, 658-670. [CrossRef]

18. Chaudry, M.; Jenkins, N.; Strbac, G. Multi-time period combined gas and electricity network optimisation. Electr. Power Syst. Res. 2008, 78, 1265-1279. [CrossRef]

19. An, S.; Li, Q.; Gedra, T.W. Natural Gas and Electricity Optimal Power Flow. In Proceedings of the IEEE Power Engineering Society Transmission and Distribution Conference, Dallas, TX, USA, 7-12 September 2003; Volume 1, pp. 138-143.

20. Salimi, M.; Ghasemi, H.; Adelpour, M.; Vaez-ZAdeh, S. Optimal planning of energy hubs in interconnected energy systems: A case study for natural gas and electricity. IET Gener. Transm. Distrib. 2014, 9, 695-707. [CrossRef]

21. Zhou, X.; Guo, C.; Wang, Y.; Li, W. Optimal expansion co-planning of reconfigurable electricity and natural gas distribution systems incorporating energy hubs. Energies 2017, 10, 124. [CrossRef]

22. Barati, F.; Seifi, H.; Sepasian, M.S.; Nateghi, A.; Shafie-Khah, M.; Catalao, J.P.S. Multi-Period Integrated Framework of Generation, Transmission, and Natural Gas Grid Expansion Planning for Large-Scale Systems. IEEE Trans. Power Syst. 2015, 30, $2527-2537$. [CrossRef]

23. Qiu, J.; Yang, H.; Dong, Z.Y.; Zhao, J.H.; Meng, K.; Luo, F.J.; Wong, K.P. A Linear Programming Approach to Expansion Co-Planning in Gas and Electricity Markets. IEEE Trans. Power Syst. 2016, 31, 3594-3606. [CrossRef]

24. Chen, H.; Baldick, R. Optimizing short-term natural gas supply portfolio for electric utility companies. IEEE Trans. Power Syst. 2007, 22, 232-239. [CrossRef]

25. Massé, P.; Gibrat, R. Application of Linear Programming to Investments in the Electric Power Industry. Manag. Sci. 2016, 3 , 149-166. [CrossRef]

26. Oree, V.; Sayed Hassen, S.Z.; Fleming, P.J. Generation expansion planning optimisation with renewable energy integration: A review. Renew. Sustain. Energy Rev. 2017, 69, 790-803. [CrossRef]

27. Sadeghi, H.; Rashidinejad, M.; Abdollahi, A. A comprehensive sequential review study through the generation expansion planning. Renew. Sustain. Energy Rev. 2017, 67, 1369-1394. [CrossRef]

28. Ringkjøb, H.K.; Haugan, P.M.; Solbrekke, I.M. A review of modelling tools for energy and electricity systems with large shares of variable renewables. Renew. Sustain. Energy Rev. 2018, 96, 440-459. [CrossRef]

29. Van Stiphout, A.; De Vos, K.; Deconinck, G. The Impact of Operating Reserves on Investment Planning of Renewable Power Systems. IEEE Trans. Power Syst. 2017, 32, 378-388. [CrossRef]

30. Aghaei, J.; Akbari, M.A.; Roosta, A.; Gitizadeh, M.; Niknam, T. Integrated renewable-conventional generation expansion planning using multiobjective framework. IET Gener. Transm. Distrib. 2012, 6, 773-784. [CrossRef]

31. Jirutitijaroen, P.; Singh, C. Reliability and cost tradeoff in multiarea power system generation expansion using dynamic programming and global decomposition. IEEE Trans. Power Syst. 2006, 21, 1432-1441. [CrossRef]

32. Gorenstin, B.G.; Campodonico, N.M.; Costa, J.P.; Pereira, M.V.F. Power System Expansion Planning Under Uncertainty. IEEE Trans. Power Syst. 1993, 8, 129-136. [CrossRef]

33. Løken, E. Use of multicriteria decision analysis methods for energy planning problems. Renew. Sustain. Energy Rev. 2007, 11, 1584-1595. [CrossRef]

34. Bucksteeg, M.; Niesen, L.; Weber, C. Impacts of dynamic probabilistic reserve sizing techniques on reserve requirements and system costs. IEEE Trans. Sustain. Energy 2016, 7, 1408-1420.

35. Zhou, Z.; Botterud, A. Dynamic scheduling of operating reserves in co-optimized electricity markets with wind power. IEEE Trans. Power Syst. 2014, 29, 160-171. [CrossRef]

36. Bruninx, K.; Van den Bergh, K.; Delarue, E.; D’haeseleer, W. Optimization and allocation of spinning reserves in a low-carbon framework. IEEE Trans. Power Syst. 2015, 31, 872-882. [CrossRef]

37. De Vos, K.; Stevens, N.; Devolder, O.; Papavasiliou, A.; Hebb, B.; Matthys-Donnadieu, J. Dynamic dimensioning approach for operating reserves: Proof of concept in Belgium. Energy Policy 2019, 124, 272-285. [CrossRef]

38. Qiu, T.; Xu, B.; Wang, Y.; Dvorkin, Y.; Kirschen, D.S. Stochastic Multistage Coplanning of Transmission Expansion and Energy Storage. IEEE Trans. Power Syst. 2017, 32, 643-651. [CrossRef] 
39. Ghofrani, M.; Arabali, A.; Etezadi-Amoli, M.; Fadali, M.S. A framework for optimal placement of energy storage units within a power system with high wind penetration. IEEE Trans. Sustain. Energy 2013, 4, 434-442. [CrossRef]

40. Soares, A.; Perez, R.; Morais, W.; Binato, S. Addressing the Time-Varying Dynamic Probabilistic Reserve Sizing Method on Generation and Transmission Investment Planning Decisions. arXiv 2019, arXiv:1910.00454.

41. Poncelet, K.; Delarue, E.; Duerinck, J.; Six, D.; D'haeseleer, W. The Importance of Integrating the Variability of Renewables in Long-Term Energy Planning Models. TME Working Paper-Energy and Environment. 2014, pp. 1-18. Available online: https://www.mech.kuleuven.be/en/tme/research/energy_environment/Pdf/wp-importance.pdf (accessed on 1 September 2021).

42. International Renewable Energy Agency. Planning for the Renewable Future: Long-Term Modelling and Tools to Expand Variable Renewable Power in Emerging Economies. 2017. Available online: https:/ /www.irena.org/publications/2017/Jan/Planning-forthe-renewable-future-Long-term-modelling-and-tools-to-expand-variable-renewable-power (accessed on 1 September 2021).

43. Pineda, S.; Morales, J.M. Chronological time-period clustering for optimal capacity expansion planning with storage. IEEE Trans. Power Syst. 2018, 33, 7162-7170. [CrossRef]

44. Rockafellar, R.T.; Uryasev, S. Optimization of Conditional Value-at-Risk. The Magazine of the Fine Arts, 2 January $1999 ; 1-26$.

45. Noakes, D.J.; McLeod, A.I.; Hipel, K.W. Forecasting monthly riverflow time series. Int. J. Forecast. 1985, 1, 179-190. [CrossRef]

46. Dias, J.A.; Machado, G.; Soares, A.; Garcia, J.D. Modeling Multiscale Variable Renewable Energy and Inflow Scenarios in Very Large Regions with Nonparametric Bayesian Networks. arXiv 2020, arXiv:2003.04855. 